University of South Carolina

Scholar Commons

$3-17-2010$

\title{
Climate Change, Environmental Justice, and Vulnerability: An Exploratory Spatial Analysis
}

\author{
Sacoby M. Wilson \\ University of South Carolina - Columbia \\ Roland Richard \\ University of South Carolina - Columbia \\ Lesley Joseph \\ University of South Carolina - Columbia \\ Edith M. Williams \\ University of South Carolina - Columbia, willi425@mailbox.sc.edu
}

Follow this and additional works at: https://scholarcommons.sc.edu/

sph_epidemiology_biostatistics_facpub

Part of the Public Health Commons

\section{Publication Info}

Published in Environmental Justice, ed. Sylvia Hood Washington, Volume 3, Issue 1, 2010, pages 13-19. This is a copy of an article published in Environmental Justice (C) 2010 Mary Ann Liebert, Inc.; Environmental Justice is available online at: http://online.liebertpub.com.

Wilson, S.M., Joseph, L., Richard, R., Williams, E.M.(2010) Climate Change, Environmental Justice, and Vulnerability: An Exploratory Spatial Analysis. Environmental Justice 3(1), 13-19.

This Article is brought to you by the Epidemiology and Biostatistics at Scholar Commons. It has been accepted for inclusion in Faculty Publications by an authorized administrator of Scholar Commons. For more information, please contact digres@mailbox.sc.edu. 


\title{
Climate Change, Environmental Justice, and Vulnerability: An Exploratory Spatial Analysis
}

\author{
Sacoby M. Wilson, Roland Richard, Lesley Joseph, and Edith Williams
}

\begin{abstract}
Research has demonstrated that vulnerable populations including disadvantaged populations of color live in areas that may place them at higher risk of exposure to social and environmental hazards. Due to climate change, these populations may experience worse health outcomes and environmental health disparities. The purpose of this project was to explore the use of Geographic Information Systems (GIS) to assess areas that may be vulnerable to climate change across the United States. We employed ArcGIS 9.3 to create vulnerability scores for areas across the country that may be that may be impacted by climate change at the county level in the United States using different social, environmental, and health indicators. We included data on race/ethnicity and socioeconomic status from the US Census. Data on pollution sources and pollution levels were obtained from the United States Environmental Protection Agency. Health data were obtained from the Behavioral Risk Factor Surveillance System (BRFSS), the National Vital Statistics System, and the National Center for Health Statistics. We also employed the Moran's I statistic to assess any significant vulnerability clusters. We found the highest scores for counties in the South particularly the Deep South and in Metropolitan areas in the Northeast and Midwest. Our findings provide insight into the areas of the country that may be vulnerable to the impacts of climate-change. More work needs to be performed to improve the spatial resolution of the maps and include more physical data that will help target areas that need effective climate change related mitigation and adaptation policies.
\end{abstract}

\section{INTRODUCTION}

$C$ LIMATE CHANGE is any long-term significant change in the expected patterns of average weather (i.e., temperature, wind speed, humidity, precipitation, tornadic activity) of a specific region or the Earth due to natural or anthropogenic activities. Rising temperatures are one of the main results of climate change. For the continental United States, the average frequency of heat waves has increased over the past 40 years (Gaffen and Ross, 1998). For the past thirty years, research has shown that a rela-

Dr. Wilson is Research Assistant Professor at the Institute for Families in Society at the University of South Carolina in Columbia, South Carolina. Mr. Richard is in the Department of Epidemiology and Biostatistics at the University of South Carolina. Mr. Joseph is in the Department of Civil and Environmental Engineering at the University of South Carolina. Dr. Williams is Research Assistant Professor in the Department of Epidemiology and Biostatistics at the University of South Carolina. tionship exists between increasing temperature variability and rates of morbidity and mortality (Gaffen and Ross, 1998; Chestnut et al., 1998; Whitman et al., 1997; Jones et al., 1982; Semenza et al., 1996; Applegate et al., 1981; MacFarlane and Walker, 1976; Ellis, 1972; McGeehin and Mirabelli, 2001). On average, 240 heat-related deaths occur annually in the United States (McGeehin and Mirabelli, 2001) and with an increase in average temperatures across the country, those numbers are presumed to increase in the foreseeable future. Typically, during periods of excessive heat, emergency rooms report an overall increase in visits, mainly for fainting, nausea, dizziness, and heat cramps (Semenza et al., 1996).

Several studies have also shown that during heat waves, there are large increases in hospital visits for cardiovascular diseases and increases in deaths due to cardiovascular and respiratory diseases (Applegate et al., 1981; MacFarlane and Walker, 1976; Ellis and Nelson, 1978). These studies suggest that sudden increases in temperature exacerbate these health conditions. While all populations will be affected by rising temperatures and 
subsequent climate variability, cities with cooler climates tend to experience more heat-related deaths than those in warmer climates (Chestnut et al., 1998; Kalkstein and Greene, 1997, which intuitively implies that adaptive measures can be taken to curtail the adverse health effects of increased temperatures. However, even in cities with traditionally hot climates, the overall heat effect on the population may overcome many adaptive measures, such as air-conditioning, and lead to increased mortality (Braga et al., 2002).

Many disadvantaged populations of color, particularly poor African Americans, may be at higher risks of experiencing the negative effects of climate change and related environmental health disparities (McGeehin and Mirabelli, 2001; Frumkin et al., 2008; Hoerner and Robinson, 2008). According to the 2000 Census Bureau, the highest percentage of African Americans are found in the states that are susceptible to Atlantic hurricanes, such as Mississippi, Louisiana, South Carolina, Georgia, Maryland, and Alabama (McKinnon, 2000). This places millions of African Americans in danger during the hurricane season. With many of them under economic duress, recovery from these hurricanes and tropical storms can be very difficult physically, emotionally, and psychologically as experienced with Hurricanes Rita and Katrina (Kessler et al., 2006; Cutter, nd; Weisler et al., 2006; Coker et al., 2006).

Many socially disadvantaged populations live in densely urbanized areas that are vulnerable to climate change because these areas tend to experience higher temperatures than surrounding areas. Many researchers have called this the "urban heat island effect" and defined it as "the existence of higher temperatures due to the abundance of heat-retaining surfaces, such as concrete and asphalt" (McGeehin and Mirabelli, 2001; Hoerner and Robinson, 2008; Haines and Patz, 2004). The Census Bureau has documented that over $43 \%$ of African Americans live in these urban "heat islands," compared to only $20 \%$ of whites (Bureau of Labor Statistics and U.S. Census Bureau, 2004). These higher temperatures pose an additional threat to poor because they will be less likely to have access to air-conditioning, insulation, or the financial means to invest in housing upgrades that can help them adapt to extreme heat conditions ( $\mathrm{O}^{\prime} \mathrm{Neill}$ et al., 2005; O'Neill, 2003; Klinenberg, 2002). Therefore, they may have an increased risk of heat-related illnesses such as heat stroke and cardiopulmonary diseases.

The purpose of this study was to explore the use of Geographic Information Systems (GIS) to assess areas that may be vulnerable to climate change due to the concentration of disadvantaged populations of color and social and environmental hazards and to discuss policy approaches to address the impacts of climate change on these vulnerable and disadvantaged populations.

\section{METHODS}

Use of Geographic Information Systems (GIS) to develop vulnerability maps

ArcGIS Version 9.3 (ESRI, Inc., Redlands, CA) was used to perform the exploratory analysis of vulnerability to climate change at the county level in the United States. The mean vulnerability score was derived from 39 variables. Data for population density, poverty level, population by age, and population by race/ethnicity were obtained from the Current Population Survey (CPS) conducted by the US Census Bureau. Population density was used because counties with higher population densities may also be more urbanized and would be impacted by the urban heat island effect. Age variables were included because children and elderly would be at risk from negative external stimuli such as climate perturbations such as heat waves and natural disasters. We included race/ethnicity because race captures negative social processes experienced by populations of color including racism and discrimination and social disadvantage. Socioeconomic status (SES) was also included because lowSES populations may have fewer resources available to help them adapt to climate change, poor housing stock, and limited access to health resources that can help them overcome climate change impacts. Additionally, segregation was added because segregation concentrates social and economic disadvantage and environmental risks. Segregated populations with limited salutogenic (i.e., health-promoting) resources (Wilson, 2009; Gee and Payne-Sturges, 2004) may be less resilient to the impacts of climate change.

In addition, several health status and risk factor variables were used to highlight counties with racial/ethnic health disparities, medically underserved, medically fragile populations, and populations at-risk to climate change to underlying health conditions. These variables include $\%$ difference in black-white infant mortality, \% Medicaid beneficiaries, heat-related mortality rate, primary care physician rate, diabetes prevalence, low birth rate, and CVD mortality to name a few. Of the 39 variables used in the risk mapping, 22 were health-related variables. These variables were obtained from the Behavioral Risk Factor Surveillance System (BRFSS), 20002006. Mortality data are from the National Vital Statistics System, National Center for Health Statistics, 1994-2003. Death rates are age-adjusted to the year 2000 standard and were calculated by Health Research and Services Administration.

Populations burdened by air pollution particularly US Environmental Protection Agency (EPA) criteria air pollutants (CAPs) (e.g., $\mathrm{PM}_{2.5}, \mathrm{PM}_{10}, \mathrm{O}_{3}, \mathrm{NO}_{2}$, and $\mathrm{SO}_{2}$ ) may have increased risk of respiratory disease and climaterelated impacts. Data from 2000 was used in the risk maps. Toxic Release Inventory (TRI) data (in pounds of total chemical releases) was extracted using the EPA TRI Data Explorer software for the year 2005. Both CAP and TRI levels have been shown to differentially burden environmental justice (EJ) populations (Gee and PayneSturges, 2004; Payne-Sturges and Gee, 2006; MorelloFrosch and Lopez, 2006) whose health risks will be magnified because of climate change.

Each variable was assigned a quintile value of 1 to 5 , with 1 representing the least vulnerability and 5 representing the greatest vulnerability. For example, counties with death rates in the lowest quintile (lowest 20\%) 
are assigned a score of 1 , whereas counties with death rates in the highest quintile (highest 20\%) are assigned a score of 5. Quintiles were created using the UNIVARIATE procedure in SAS 9.2 (SAS Institute, Cary, NC). The mean vulnerability score was then obtained from the sum of the 39 risk variables. In addition, to analyze the any spatial patterns that are observed in the composite vulnerability map, we employed a local cluster analysis. We used the Moran's I statistic in the ArcGIS 9.3 platform to show the location of contiguous areas of similar vulnerability (either low or high).

\section{RESULTS}

\section{GIS vulnerability mapping}

Figure 1 shows the mean vulnerability score for each county in the United States. The map is divided into four US Census defined regions: the South, Midwest, Northeast, and West. The vulnerability score indicates the degree that which populations within each county particularly e.g., low-income, disadvantaged groups, children, elderly, populations burdened by health disparities, and the medically underserved will be at risk from the negative environmental and health effects of climate change. The mean vulnerability score was obtained from the sum of quintile values assigned to each variable with 5 being the greatest vulnerable and 1 being the least vulnerable. The vulnerability scores for each county ranged from 1.2 to 4.4 ; with 4.4 representing the greatest vulnerability.

The results of spatial analysis showed that 15 of the 25 highest vulnerability scores, including the 7 highest vul- nerability scores were in counties/parishes in the South region. The South region includes Baltimore City, MD; Jefferson County, AR; Jefferson County, AL; and Caddo Parish, LA all tied for the highest overall vulnerability score (4.4). Despite having 15 counties at the top of the vulnerability score scale, the south region (3.04), did not have the highest overall regional score. The Northeast region had the highest mean score of 3.25 , followed by the South (3.04), the West (2.79), and the Midwest (2.75). As stated previously, several areas in the South region had high-vulnerability scores. Most notably, nearly $58.7 \%$ of the counties in South Carolina (27 of 46) fell in the highest quintile, while $48 \%$ of Louisiana's parishes (31 of 64 ) also fell in the highest quintile. Florida, particularly the peninsula region, also had a high concentration of highvulnerability counties with $52 \%$ (35 of 67 ). Arizona (60\%) and California (46.5\%) had the highest concentrations of high vulnerability counties in the West region.

The Midwest region showed high scores in counties comprising the metropolitan areas of St. Louis, MO; Cleveland, $\mathrm{OH}$; and Detroit, MI. Additionally, there were high concentrations of high vulnerability counties in the Bootheel region of Missouri (SE Missouri) and extreme Eastern Ohio. Notable areas of high vulnerability in the Northeast region are Southern New Jersey and much of Metropolitan Philadelphia, PA, New York City, and counties along the Hudson River in Upstate New York.

Much like the county level measures, the South had a great number of states among the 10 highest state mean scores, with 7. Delaware (3.9), Washington, DC (3.9), South Carolina (3.6), Florida (3.5), Louisiana (3.5), Alabama (3.4), and Maryland (3.4) were all among the 10

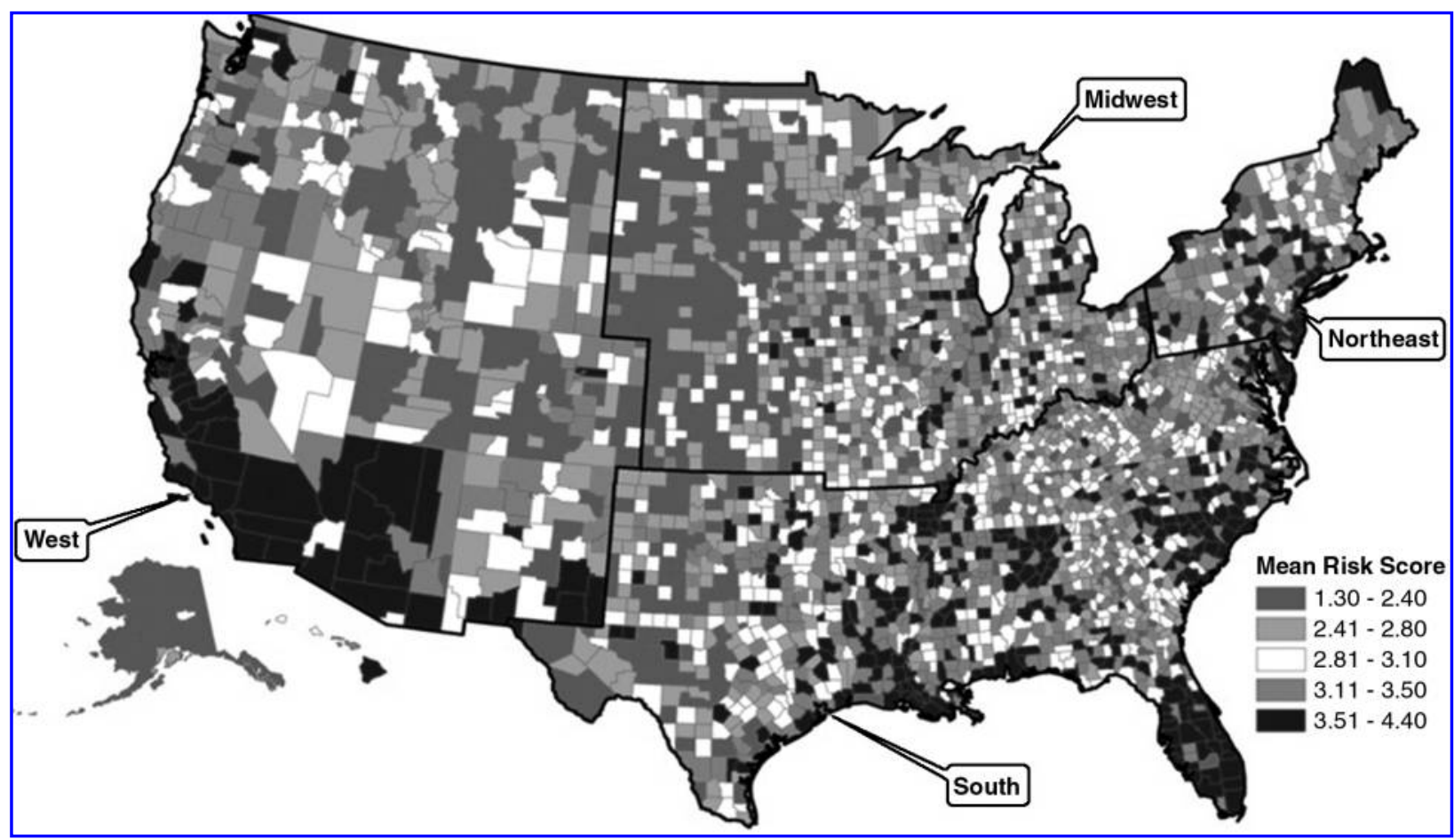

FIG. 1. Climate change risk scores at the county level for the United States. 
highest overall mean vulnerability scores by state. Also in the top ten were three Northeastern states: New Jersey (3.56), Connecticut (3.49), and Massachusetts (3.36). The states with lowest mean scores were primarily in the West and Midwest regions. These states include Utah (2.58), Minnesota (2.56), Colorado (2.49), Kansas (2.49), North Dakota (2.43), Montana (2.40), South Dakota (2.36), Nebraska (2.36), and Alaska (1.99). Other states such as Wyoming (2.70), Nevada (2.71), Idaho (2.71), and Iowa (2.72) also had low mean vulnerability scores. Even though a majority of the counties and the states in the South had high vulnerability scores, there were also a large number of counties located in Southern states such as Texas, West Virginia, Kentucky, and Virginia that had low vulnerability scores.

Figure 2 shows statistically significant clusters of high and low vulnerability by county, with significantly high clusters having a Moran's I Z-score between 21.9 and 45.8. Notable areas with statistically significant highvulnerability clusters are counties/parishes in the coastal areas of Louisiana, Mississippi, and Alabama, as well as much of South Carolina. There was also a highly significant cluster in the plains states (North and South Dakota, Nebraska, and Kansas).

\section{DISCUSSION}

\section{GIS vulnerability mapping}

There is a wealth of evidence on the existence and impacts of climate change. A large portion of the current research explored the regional differences of the effects of climate change, suggesting that each particular region of the United States can expect varying results (Chestnut et al., 1998; McGeehin and Mirabelli, 2001; Braga et al., 2002; Curriero et al., 2001; Patz et al., 2000; Patz and Olson, 2006; Bell et al., 2007) and but provided limited evidence of how social disadvantaged populations particularly EJ populations would be more vulnerable to the impacts of climate change. Several peer-reviewed articles compared and contrasted health disparities among racial/ethnic groups (Chen et al., 2002; Mays et al., 2007; Williams et al., 1997; Perilla et al., 2002) but none specifically address the health risks and magnification of these disparities due to climate change.

To fill this gap, we used GIS to develop a spatial index of vulnerability for different regions and states in the country at the county level with a focus on disadvantaged populations of color. The final vulnerability map is a composite map of population, health, and environmental indicators. The final map shows high vulnerability in the Southern states with larger numbers of people of color, more exposure to the coasts, and more poor people and medically underserved populations with health disparities. We also observed high vulnerability in metropolitan areas in the Midwest and Northeast probably due to segregation and high population density in these areas. The final vulnerability map was weighted more towards where there are disadvantaged populations of color particularly African Americans which may have influenced the spatial clustering of areas with significantly high vulnerability scores in the South and Midwest. Also, only using black-white dissimilarity index as the segregation

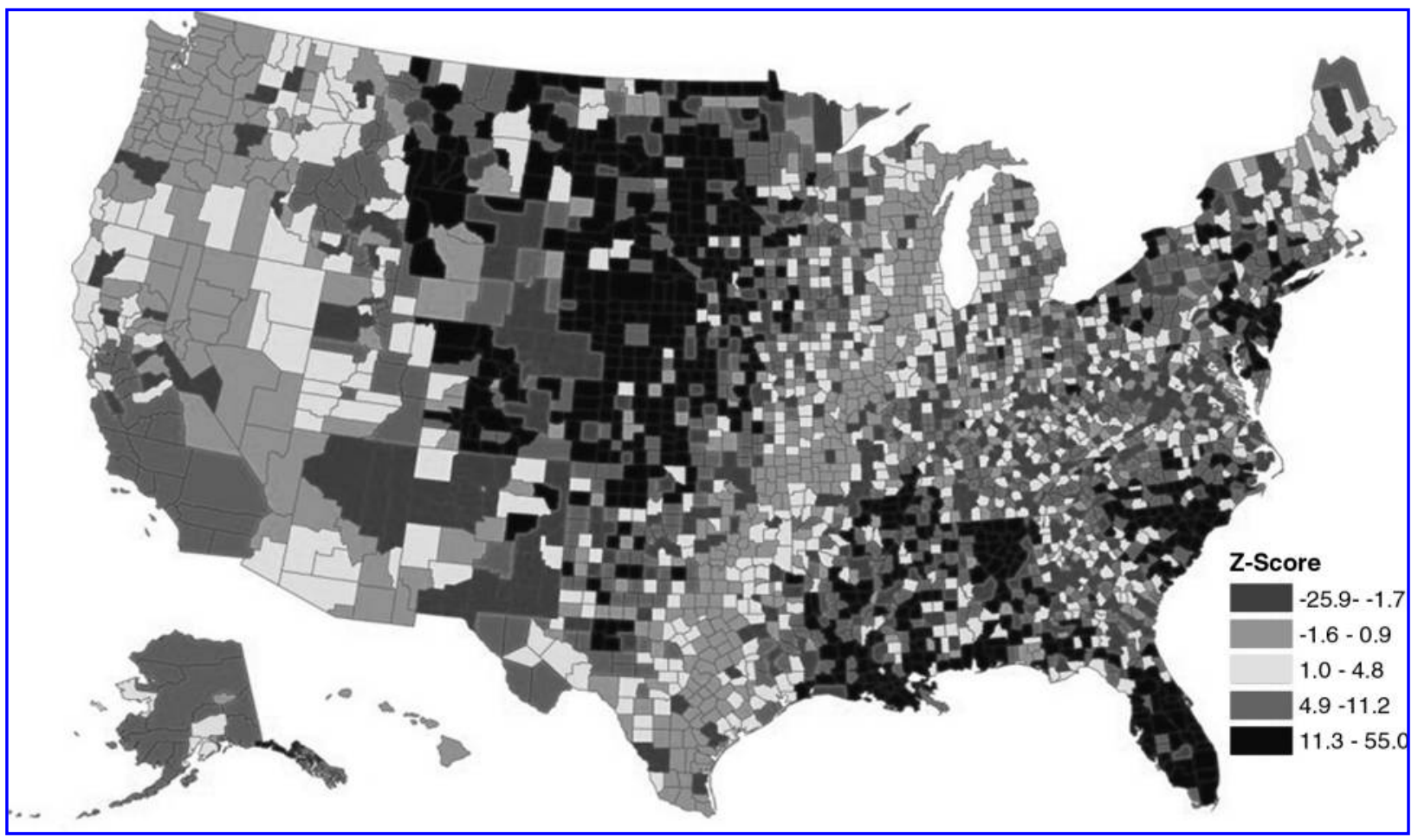

FIG. 2. Moran's I analysis of mean risk score by county for the United States. 
measure and black-white differences in previously mentioned health outcomes may have magnified vulnerability in certain regions. In future research, we will explore developing vulnerability maps for other groups of color such as Hispanics using Hispanic-white segregation index and Hispanic-white health disparity measures. In addition to provide a more accurate spatial depiction of vulnerability for all non-whites, we will utilize a multi-group segregation measure and composite health disparity maps comparing whites vs non-whites.

Another limitation of focusing primarily on racial/ ethnic health disparities to help establish population vulnerability to climate change and risk is this may inflate or skew the county level scores. The use of these maps may have increased or decreased vulnerability in the final composite map when we may have expected a different vulnerability score based on our a priori knowledge about particularly regions in the country. For example, we expected West Virginia to have a higher average score because of the concentration of poor whites in the state and in Appalachia. In future analyses, we will perform analyses with SES-related health disparity measures and also exclude segregation measures to examine the spatial variability of vulnerability to climate change for economically disadvantaged populations.

We did include information on pathogenic environmental exposures including data on levels of TRI releases and CAP emissions because many of these chemicals are greenhouse gases (GHGs) that can cause climate change and increase a population's vulnerability to climate change related impacts. However, we did not include other environmental indicators such as temperature trends, a digital elevation model (DEM) and use/land cover (LULC) which is a limitation of the spatial vulnerability analysis. Without the temperature data, we do not have an accurate assessment of peak temperature levels and frequency of heat waves which can cause increases in hospitalizations, emergency room visits, and mortality for children, elderly, and populations with co-morbidities. Without the DEM and LULC data, we do not have accurate information on places that are at-risk from flooding, changes in sea level, and the urban heat island effect. Also, not having the LULC data may inflate risk scores because we did not use data that presents the spatial distribution of vegetation (e.g., green space) at the county level. This "green space" could act to decrease temperature levels and reduce the urban heat island effect which is particularly important in densely populated U.S. cities and segregated metropolitan regions.

We will include these environmental indicators and data on natural disasters (e.g., floods, tornadoes, hurricanes, fires, blizzards) used in previous studies of national-level mortality and social vulnerability trends (Cutter et al., 2003; Borden and Cutter, 2008) in future research. Even though natural disasters data was not used, we believe that several states with high scores such as Louisiana, Florida, South Carolina, Alabama, New Jersey, Mississippi, and Delaware are states that may be vulnerable to more intense and frequent natural disasters due to their proximity to coastal areas. Another limitation of this analysis is that data for county-level objects are often aggregations of individual level information. Ecological fallacy occurs when analyses based on grouped data lead to conclusions different from those based on individuals. Therefore, the spatial patterns derived from this analysis may include aggregation bias due to the differential distribution of confounding variables created by grouping (Cromley and McLafferty, 2002). For example, a recent study (Reid et al., 2009) performed heat-related vulnerability mapping in the U.S. using census tract level data. The use of census tract data provides better spatial resolution than county level data and vulnerability scores that may be more relevant for populations at the neighborhood level. However, because of the environmental public health tracking implications, national health agencies and county health departments may find the exploratory approach described in this study useful.

\section{Climate change policy}

Even with these limitations, the use of GIS to construct vulnerability maps provides important information that can be used to help develop climate change adaptation and mitigation policies particularly for socially disadvantaged populations. Recently, cap and trade has been touted as a mitigation approach that can be used to reduce GHG emissions and thus reduce the impacts of climate change by the US government, industry, and environmental groups as seen by the United States Climate Action Partnership (USCAP) which was co-founded by the Environmental Defense Fund in 2007. The program consists of placing a cap on emissions of GHGs that can lead to climate change and the trading of permits between businesses that are releasing GHGs below their cap to businesses that are releasing GHGs above their specific cap. This program could potentially lead to a significant reduction in GHG emissions over the next fifty years, but critics believe that the costs of reducing pollution emissions will be shifted from industry to consumers and lead to higher energy costs and push families into poverty. This is an important point but it does not capture the problems that EJ communities have with the program. EJ communities are already disproportionately burdened by pollution-emitting industries and this cap-and-trade system could lead to major polluters trading to release more pollution. If this happens, these areas could eventually become non-attainment zones for criteria air pollutants (CAPs) such as $\mathrm{PM}_{2.5}$ and ozone and create climate change hotspots. Geographic Information Systems could be used to map potential hotspots by taking into account the spatial distribution of the largest GHG emitters and weighting the vulnerability scores by adding in attainment status for criteria air pollutants in these regions.

Concerns about cap-and-trade legislation were recently raised at a groundbreaking climate justice conference hosted by WE ACT in New York in January 2009 (www.weact.org). Many EJ activists and advocates at this meeting believe that cap and trade would reward polluters for failing at meeting their emission caps and preferred cap and dividend over cap and trade. Cap and 
dividend is a program that auctions off all proceeds to the highest bidder and the monies collected are returned to the taxpayer in order to offset the rise in energy costs. In April 2009, Congressman Chris Van Hollen (D-Maryland) authored the Cap and Dividend Act of 2009. For EJ communities, this approach may be preferable particularly if special considerations are made to provide more of the dividends to communities who have been disparately burdened and impacted by air pollution emission sources as a community benefit. EJ communities have hosted more than their fair share of point and non-point air pollution sources without proper compensation for the use of their community's ecological goods and services for this purpose.

We also believe that the green economy and a growing class of "green-collar" jobs could help both the economy and efforts to reduce GHG emissions and climate change impacts in socially disadvantaged communities of color nationally. Many of these communities do not have healthy economic infrastructure which leads to high levels of underemployment and unemployment and a cycle of poverty, low educational attainment, crime, violence, and prison in these communities. The integration of the social justice and community empowerment framework of the environmental justice movement and new economic opportunities through the green economy could positively benefit the social, environmental, economic, physical, political, and mental health of these communities. From funding through the 2009 Stimulus Bill and other bills related to the green economy and alternative energy, local governments and educational institutions, particularly institutions that serve disadvantaged or underrepresented groups such as Historically Black Colleges and Universities (HBCUs), could establish green jobs training programs that will retrain low-income and unemployed workers from disadvantaged communities vulnerable to climate change in green-collar jobs related to construction, environmental assessment and testing, and local transportation and maritime industriesoperations, repair, and maintenance of marine vessels, rail, and trucks. Training could also include retrofitting diesel engines, electric engine repair and maintenance, bicycle repair, LEED certification, weatherization of buildings to make them more energy efficient, etc. The residents will be able to utilize their skills in greening their communities, reduce their exposure to outdoor ambient air, increase energy efficiency, and share in the potential wealth of the emerging clean-tech economy.

\section{CONCLUSION}

In order to gain a better understanding of the consequences of climate change, climate change scientists will need to work together with members of the public health community, particularly epidemiologists, to gather the best available data on the incidence of diseases in various populations and the degree to which these diseases can be attributed to climate change. The exploratory spatial analysis of population vulnerability to climate change in the United States described in this article provides some useful information on what areas will be at risk from climate change impacts. More work needs to be done in future research to include physical and topographic parameters in order to improve the vulnerability scores so that mitigation and adaptation policies can be better targeted to the most vulnerable, susceptible, and disadvantaged communities and populations. Increased usage of GIS technologies and the upcoming 2010 US Census will be very beneficial in gaining additional climate, demographic, and health information to fully grasp the severity of the situation for vulnerable and at-risk populations particularly medically underserved populations and EJ populations.

\section{REFERENCES}

1. D. J. Gaffen and R. J. Ross. "Increased Summertime Heat Stress in the US." Nature. 1998;396: 529-530.

2. L. G. Chestnut, W.S. Breffle, J. B. Smith, and L. S. Kalkstein. "Analysis of Differences in Hot-weather-related Mortality across 44 US Metropolitan Areas." Environ Sci Policy. 1998;1: 9-70.

3. S. Whitman, G. Good, E. R. Donoghue, N. Benbow, W. Shou, and S. Mou. "Mortality in Chicago Attributed to the July 1995 Heat Wave." Am J Public Health. 1997;87: 1515-1518.

4. T. S. Jones, A. P. Liang, E. M. Kilbourne, et al. "Morbidity and Mortality Associated with the July 1980 Heat Wave in St. Louis and Kansas City, Mo." I Amer Med Assoc. 1982;247: 3327-3331.

5. J. C. Semenza, C. H. Rubin, K. H. Falter, et al. "Heatrelated Deaths during the July 1995 Heat Wave in Chicago." N Engl J Med. 1996;335: 84-90.

6. W. B. Applegate, J. W. Runyan, Jr., L. Brasfield, M. L. Williams, C. Konigsberg, and C. Fouche. "Analysis of the 1980 Heat Wave in Memphis." J Am Geriatr Soc. 1981;29: 337-342.

7. A. MacFarlane and R. E. Walker. "Short Term Increases in Mortality during Heatwaves." Nature. 1976;264: 434436.

8. F. P. Ellis. "Mortality from Heat Illness and HeatAggravated Illness in the United States." Environ Res. 1972;5: 1-58.

9. M. A. McGeehin and M. Mirabelli. "The Potential Impacts of Climate Variability and Change on Temperaturerelated Morbidity and Mortality in the United States." Environ Health Perspect. 2001;109(suppl. 2): 185-189.

10. F. P. Ellis and F. Nelson. "Mortality in the Elderly in a Heat Wave in New York City, August 1975." Environ Res. 1978;15: 504-512.

11. L. S. Kalkstein and J. S. Greene. "An Evaluation of Climate/Mortality Relationships in Large US Cities and the Possible Impacts of a Climate Change." Environ Health Perspect. 1997;105: 84-93.

12. A.L. Braga, A. Zanobetti, and J. Schwartz. "The Effect of Weather on Respiratory and Cardiovascular Deaths in the US Cities." Environ Health Perspect. 2002;110: 859-863.

13. H. Frumkin, J. Hess, G. Luber, J. Malilay, and M. McGeehin. "Climate Change: The Public Health Response." Am J Public Health. 2008; 98: 435-445.

14. J. A. Hoerner and N. Robinson. A Climate of Change: African-Americans, Global Warming, and a Just Climate 
Policy for the US. Oakland, CA: Environmental Justice and Climate Change Initiative; 2008. Available at: <http:// www.ejcc.org/climateofchange.pdf $>$. Accessed March 15, 2009.

15. J. McKinnon, U.S. Census Bureau. Census 2000 Brief. The Black Population: 2000. Available at: $<$ http://www.census .gov/prod/2001pubs/c2kbr01-5.pdf > . Accessed April 1, 2009.

16. R. C. Kessler et al. "Mental Illness and Suicidality After Hurricane Katrina." Bull World Health Organ. 2006;84(12): 930-939.

17. S. Cutter. The Geography of Social Vulnerability: Race, Class, and Catastrophe. Available at <http:// understandingkatrina.ssrc.org/Cutter/>. Accessed April $1,2009$.

18. Weisler et al. "Mental Health and Recovery in the Gulf Coast After Hurricanes Katrina and Rita." JAMA. 2006;296: 585-588.

19. A. Coker, J. Hanks, K. Eggleston, J. Risser, P. Tee, K. Chronister, C. Troisi, R. Arafat, and L. Franzini. "Social and Mental Health Needs Assessment of Katrina Evacuees." Disaster Management E Response. 2006;4(3): 88-94.

20. A. Haines and J. A. Patz. "Health Effects of Climate Change." L Amer Med Assoc. 2004;291: 99-103.

21. Bureau of Labor Statistics and U.S. Census Bureau. Current Population Survey, 2004. Available at: <http://www .census.gov/cps/ and http://dataferrett.census.gov/>. Accessed March 15, 2009.

22. M. S. O'Neill, A. Zanobetti, and J. Schwartz. "Disparities by Race in Heat-related Mortality in Four US cities: The Role of Air Conditioning Prevalence." J Urban Health. 2005;82(2): 191-7.

23. M. S. O'Neill. "Air Conditioning and Heat-Related Health Effects." Appl Environ Sci Publ Health. 2003;1(1): 9-12.

24. E. Klinenberg. Heat Wave: A Social Autopsy of Disaster in Chicago. Chicago, IL: The University of Chicago Press, 2002.

25. S. M. Wilson. "A Holistic Ecologic Framework to Study and Address Environmental Justice and Community Health Issues." Environmental Justice. 2009;2(1): 1-9.

26. G. C. Gee and D. Payne-Sturges. "Environmental Health disparities: A Framework Integrating Psychosocial and Environmental Concepts." Environ Health Perspect. 2004; 112: 1645-1653.

27. D. Payne-Sturges and G. Gee. "National Environmental Health Measures for Minority and Low Income Populations: An Approach for Tracking Environmental Health Disparities." Environ Res. 2006;102: 154-171.

28. R. Morello-Frosch and R. Lopex. "The Riskscape and the Color Line: Examing the Role of Segregation in Environmental Health Disparities." Environ Res. 2006;102: 181-196.
29. F. C. Curriero, J. A. Patz, J. B. Rose, and S. Lele. "The Association between Extreme Precipitation and Waterborne Disease Outbreaks in the United States, 19481994." Am J Public Health. 2001;91: 1194-1199.

30. J. A. Patz, D. Engelberg, and J. Last. "The Effects of Changing Weather on Public Health." Annu Rev Publ Health. 2000;21: 271-307.

31. J. A. Patz and S. H. Olson. "Climate Change and Health: Global to Local Influences on Disease Risk." Ann Trop Med Parasitol. 2006;100: 535-549.

32. M. L. Bell, R. Goldberg, C. Hogrefe, et al. "Climate Change, Ambient Ozone, and Health in 50 US Cities." Climatic Change. 2007;82: 61-76.

33. J. T. Chen, N. Krieger, S. K. Van Den Eeden, and C. P. Quesenberry. "Different Slopes for Different Folks: Socioeconomic and Racial/Ethnic Disparities in Asthma and Hay Fever among 173,859 U.S. Men and Women." Environ Health Perspect. 2002;110: 211-216.

34. V. M. Mays, S. D. Cochran, and N. W. Barnes. "Race, Race-Based Discrimination, and Health Outcomes among African Americans." Annu Rev Psychol. 2007;58: 201-225.

35. D. R. Williams, Y. Yu, J. Jackson, and N. Anderson. "Racial Differences in Physical and Mental Health." J Health Psychol. 1997;2: 335-351.

36. J. L. Perilla, F. H. Norris, and E. A. Lavizzo. "Ethnicity, Culture, and Disaster Response: Identifying and Explaining Ethnic Differences in PTSD Six Months after Hurricane Andrew." I Soc Clin Psychol. 2002;21: 20-45.

37. S. L. Cutter, B. J. Boruff, and W. L. Shirley. "Social Vulnerability to Environmental Hazards." Soc Sci Q. 2003;84(2): 242-261.

38. K. A. Borden and S. L. Cutter. "Spatial patterns of natural hazards mortality in the United States." Int J Health Geogr. 2008;7: 64-77.

39. E. K. Cromley and S. McLafferty. GIS and public health. New York, NY: Guilford Press, 2002.

40. C. E. Reid, M. S. O'Neill, C. Gronlund, S. J. Brines, D. G. Brown, A. V. Diez-Roux, and J. Schwartz. "Mapping community level determinants of heat vulnerability." Environmental Health Perspectives. Online June 11, 2009.

Address correspondence to: Sacoby Wilson

Institute for Families in Society University of South Carolina 1600 Hampton St., Suite 507 Columbia, SC 29229

E-mail: wilsons2@gwm.sc.edu 



\section{This article has been cited by:}

1. Timothy W. Collins, Sara E. Grineski, Paula Ford, Raed Aldouri, María Lourdes Romo Aguilar, Gilberto Velázquez-Angulo, Rosa Fitzgerald, Duanjun Lu. 2012. Mapping vulnerability to climate change-related hazards: children at risk in a US-Mexico border metropolis. Population and Environment . [CrossRef]

2. Winston Abara, Sacoby M. Wilson, Kristen Burwell . 2012. Environmental Justice and Infectious Disease: Gaps, Issues, and Research Needs. Environmental Justice 5:1, 8-20. [Abstract] [Full Text HTML] [Full Text PDF] [Full Text PDF with Links]

3. Sara E. Grineski, Timothy W. Collins, Paula Ford, Rosa Fitzgerald, Raed Aldouri, Gilberto Velázquez-Angulo, Maria de Lourdes Romo Aguilar, Duanjun Lu. 2011. Climate change and environmental injustice in a bi-national context. Applied Geography . [CrossRef] 